a copy, as shall delegates who attended the Congress. To others the pre-publication price has been fixed at 8.00 U.S. (Eight Dollars), but after printing the cost might be higher to those ordering copies later than publication date. It is likely that internal B.A.S.M. news and notices

Would members please note again that the correct address for all mail to the Treasurer or to the Journal should be sent to:

Dr. H. E. Robson,

39 Linkfield Road,

Mountsorrel,

Nr. LOUGHBOROUGH,

Leics. LE12 7DJ.

Tel: Rothley 2846 during surgery hours. will be published at the same time in a separate "Bulletin of the B.A.S.M." which was our original production, later incorporated into the "British Journal of Sports Medicine".

There is also a change of address to:

Kingfisher's Pool,

43 Westfield Lane,

ROTHLEY,

Leics.

Tel: Rothley 3186.

Redirection notices from Loughborough College of Education and 8 Outwoods Road, Loughborough, shall soon be expiring, and mail might easily fail to reach its destination.

\title{
THE EFFECTS OF SEVERE MUSCULAR EXERCISE ON MUSCLE INNERVATION
}

\author{
G. L. KIDD, M.Sc., Ph.D.* and E. J. CHARLESWORTH, M.Ed.** \\ * The Physiological Laboratory, The University of Liverpool. \\ ** Department of Physical Education, Chester College.
}

\begin{abstract}
The changes in composition of muscle interstitial fluid during severe exercise is discussed, and a study of the effect on muscle receptors of one such change, an increase in potassium ion concentration, is described. Results of experiments on rat muscle are presented which indicate that receptors in muscle are protected from great changes in potassium ion concentration by barrier membranes with structure and properties capable of adaptation in response to intensive muscular activity. The adaptation could delay the onset of receptor fatigue and muscle pain.
\end{abstract}

\section{Introduction}

The physiology of severe muscular activity is more than a simple extension of the physiology of moderate exercise. It is clear that new concepts are required if the adaptation of muscle to advanced forms of training is to be predicted, or even assessed. In a recent paper, we (Charlesworth \& Kidd, 1971) suggest that an increase in the ability of an athlete to tolerate the discomforts of severe anaerobic activity is one of several factors involved in the improvement following intensive training. The particular form of training cited was shuttlerunning.

In the present paper we will discuss the results of an investigation made in the Department of Physiology at the University of Liverpool of the susceptibility of muscle receptors to substances released from muscle fibres during severe activity.

If a muscle is to receive an adequate blood supply to meet the demands of activity, its vascular system must dilate. The dilatation in response to even moderate activity is near to maximal (Fig. 1). It is generally accepted that a local action by substances produced by or released from active muscle fibres is responsible for the early stage of hyperaemia: with the potassium ion $\left(\mathrm{K}^{+}\right)$as a most important agent. That ion is released from muscle fibres when they are excited, and appears in the venous effluent of maximally active muscles at a concentration double that usually found in the venous blood of muscles at rest (Kjellmer, 1961, 1965; Wildenthal, Miezuriak, Skinner \& Mitchell, 1968). Since the venous concentration is likely to be at the lower end of the range of $\mathrm{K}^{+}$concentration found in muscle interstices (Areskog, Arturson \& Grotte, 1965), some parts of the interstitial fluid are likely to contain even higher concentrations, at which, $\mathrm{K}^{+}$, because of its action on the membranes of vascular smooth muscle, is effective as a vasodilator.

If that is a true account of the major, local mechanism operating in hyperaemia, it is difficult to imagine how $\mathrm{K}^{+}$at a concentration effective on smooth muscle 


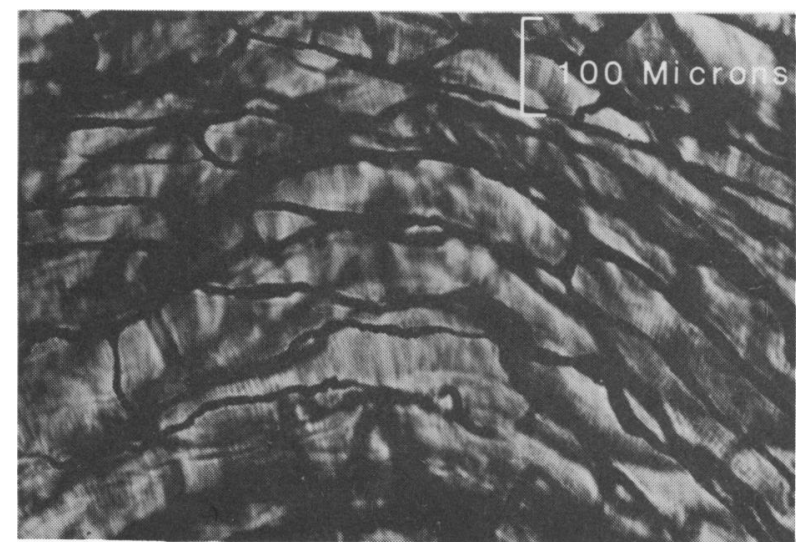

Figure 1. Maximal dilation of the vascular systems of rat caudal muscle revealed by an intra-arterial injection of india ink. Unfixed preparation in saline photographed under phase-contrast illumination.

would leave unaffected the excitability of receptors and neuromuscular junctions, and possibly also the conductivity of axons, all of which structures share the intramuscular environment.

We will argue, however, that some parts of the intramuscular nervous system exist in a special environment bounded by membranes with the ability to restrict the passage of substances likely to interfere with nervous activity, and to do so because active transport systems in cells comprising the membranes are operating. (An excellent discussion of this form of activity is contained in Merrillees, 1960). It is possible that the effectiveness of the protective systems is increased by an adaptation to the stress of severe muscle activity as their metabolism changes in parallel with those of other muscle systems.

\section{Methods}

The preparation used for the experiments is described in detail elsewhere (Gladden \& Kidd, 1969), but consists essentially of an extremely thin slip of muscle at the tail base of the rat. It is a real muscle in that it plays an important part in the postural and equilibrium mechanisms of the animal. The muscle, with its innervation and vascular systems undisturbed is arranged in a bath which can be filled with different solutions to imitate the changes in interstitial composition taking place when a muscle becomes active. This interstitial approach by active substances can be compared with the effects of an intra-arterial approach by using a modification of the preparation, in which the caudal artery supplying the muscle is catheterised (Gurumurthy \& Kidd, 1967).

A dissection of the spinal cord and its roots enables recordings to be taken of the discharge of receptor afferent activity from the muscle. The action potentials are phatographed from the screen of an oscilloscope.
The muscle mechano-receptors were excited by stretch applied to the muscle by an electro-magnetic device energised by a waveform generator. The details of this part of the preparation are contained in Kidd, Kucera \& Vaillant, 1971.

\section{Results}

The response to stretching and maintained stretch of a primary (annulospiral) ending of a muscle spindle as it is subjected to concentrations of $\mathrm{K}^{+}$above that found in resting muscle is useful as a model. With normal concentrations of $\mathrm{K}^{+}(4.5 \mathrm{mEq} / \mathrm{L})$ bathing the muscle the receptor responds by showing a distinct threshold to stretch, a pronounced dynamic sensitivity (indicated by the appearance of a cluster of high-frequency action potentials as stretch is reaching its maximum) and a regular discharge of action potentials when stretch is maintained. These features of the response are seen in Fig. 2a.

The response as the receptor equilibrates in a bathing solution containing $10 \mathrm{mEq} \mathrm{K} \mathrm{K}^{+} / \mathrm{L}$ (a concentration one could reasonably expect to find in the interstices of maximally active muscle) is seen in the remaining part of Fig. 2. The first effect is one of reduced threshold to stretch, with the action potentials appearing after 0.4 $\mathrm{mm}$ of stretch as opposed to $1-2 \mathrm{~mm}$ with normal $\mathrm{K}^{+}$ concentration. The receptor shows also an increased excitability during maintained stretch (Fig. 2b). It takes between 1.0 and $1.5 \mathrm{~min}$. for this effect to develop, and $30 \mathrm{sec}$. later, an additional increase in excitability of the receptor is seen which takes the form of the discharge of action potentials by the unstretched receptor (Fig. 2c \& 2d).

A
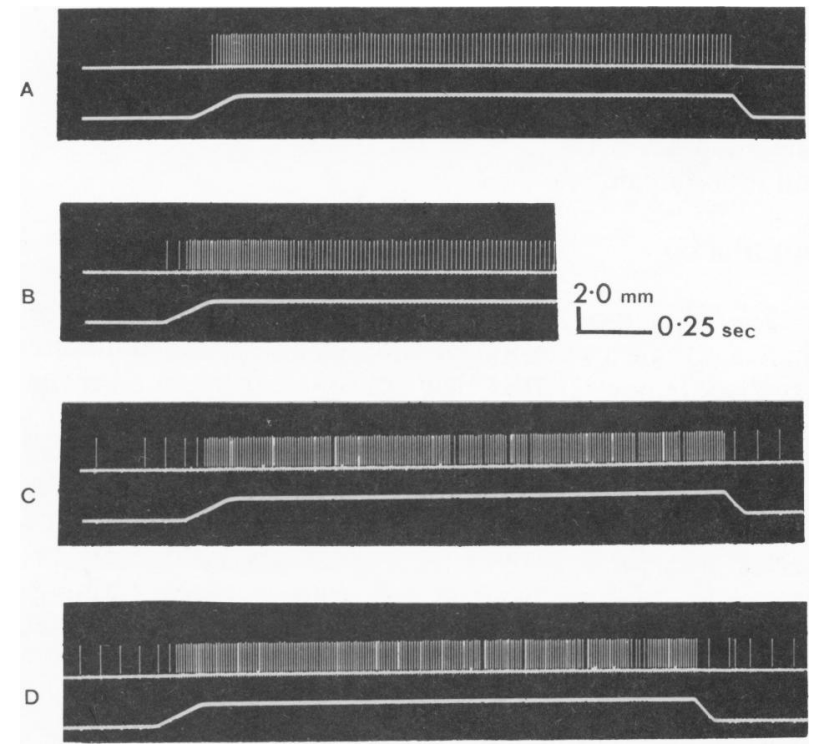

Figure 2. Action potentials discharged by a primary 
(annulospiral) receptor ending of a muscle spindle (upper trace of each record) in response to stretching through $2.0 \mathrm{~mm}$. The signal on the lower trace indicates stretching by an upward excursion.

Record $A$ was obtained with the muscle bathed in a solution containing normal potassium ion concentration. Records $B-D$ were obtained at $30 \mathrm{sec}$. intervals starting $1.5 \mathrm{~min}$. after the muscle had been subjected to $2 x$ normal potassium ion concentration.

The records of Fig. $2 c$ and $2 d$ show, however, that the enhanced excitability in response to raised $\mathrm{K}^{+}$ concentration occurs at the expense of a regular discharge during maintained stretch the irregularity of appearance of action potentials suggests interference with the essentially reliable signalling mechanisms of the stretch reflex (Sharp, 1971).

That response of the primary ending to an elevated $\mathrm{K}^{+}$concentration probably represents the full range of physiological response, being in part an adaptation and in part a tolerance. The limit of tolerance of the ending is clearly seen in the response of another primary ending to $\mathrm{K}^{+}$at a concentration of $15 \mathrm{mEq} / \mathrm{L}$, a concentration we estimate to be outside the physiological range. The response of the ending to normal $\mathrm{K}^{+}$concentration can be seen in Fig. 3a and 3b. The remaining sets of records show the effect of bathing the muscle in the $\mathrm{K}^{+}$enriched solution, and were taken at $30 \mathrm{sec}$. intervals. Fig. $3 \mathrm{c}, \mathrm{d}$, $\mathrm{e}, \mathrm{f}, \mathrm{g}$ and $\mathrm{h}$ confirm Fig. 2, but the other recordings, obtained after subjecting the receptor to the solution for between 120 and 180 sec., show that the excitability is depressed and eventually almost abolished.

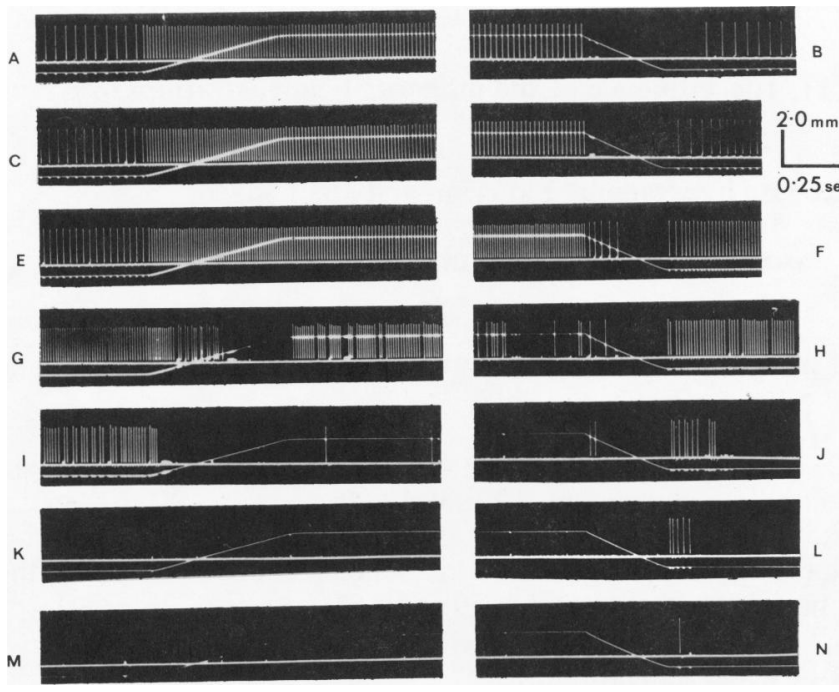

Figure 3. The form of presentation of these records is identical with those of Figure 2, but the muscle was subjected to an unusually high concentration of potas- sium ion ( $3 \times$ normal). Records $A \& B$ show the effect of stretching and relaxing the muscle in a normal solution. The remaining records were obtained at $30 \mathrm{sec}$. intervals starting 1.5 min. $(C \& D)$ after subjecting the muscle to the $3 x$ normal potassium ion concentration.

Records on the left of this figure show the effect of stretching the muscle, and those on the right show the effect of returning the muscle to its resting length. $A$ time interval of $15 \mathrm{sec}$. elapsed between the recordings (e.g. $A \& B$ ) forming each pair.

An observation, more important to our argument than the ultimate action of $\mathrm{K}^{+}$at different concentrations, is of the time course with which the effect develops. It takes between 120 and $180 \mathrm{sec}$. for $\mathrm{K}^{+}$to come into equilibrium between the bathing solution and the effective vicinity of the receptor ending. The time course for diffusion cannot account for all of this delay: the muscle is less than $1.0 \mathrm{~mm}$ in thickness and the solution bathes it on both sides. Increases in $\mathrm{K}^{+}$concentration influence the excitability of motor axon terminals in the muscle in $25-30 \mathrm{sec}$. (Kidd, Kucera \& Vaillant, 1970) and KCI, in quantities calculated to give similar concentrations in the vicinity of the receptor endings, injected into the muscle artery similarly acts in seconds. It would appear, therefore, that a barrier between the interstitial space and receptor ending can delay the rate of increase of $\mathrm{K}^{+}$concentration, and, moreover, it is a barrier which can be penetrated by a vascular approach.

\section{Discussion}

The receptor endings of the mammalian muscle spindle are enveloped in a -liquid filled capsule of considerable volume formed by membranes which are sealed around the muscular elements of the receptor and which show evidence of cell structure indicative of active transport systems (Shantha, Golanz \& Bourne, 1968; Merrillees, 1960). The endings, therefore, are inside a protective environment. Blood capillaries penetrate the membranes of the capsule but do so sparsely. Whatever concentration of $\mathrm{K}^{+}$accumulates inside the capsule of the spindle is presumably related to the transporting capacity of the spindle's circulation and not solely to the general interstitial concentration in the muscle.

But what of other receptor endings? Comparisons of the relative susceptibility of the different forms of ending in muscle (Kidd, Kucera \& Vaillant, 1971) show that, when they respond, non-proprioceptive afferents (those responsible for cardio-vascular and respiratory reflex effects and for pain) are the most rapidly affected by $\mathrm{K}^{+}$, Golgi tendon organs follow in sequence and the muscle spindle endings come last. The tendon organ possesses a capsule in some respects comparable in structure to that of the muscle spindle (Merrillees, 1961) but it lacks the voluminous liquid environment, and its 
tolerance for $\mathrm{K}^{+}$is much less than that of the spindle (Kidd \& Kucera, 1969).

The qualification, in italics, of the susceptibility of pain afferents from muscle is most important. They are present in the muscle, they are responsive to stimuli which are known to give rise to pain (Moore, Moore \& Singleton, 1934) but they do not always respond to $\mathrm{K}^{+}$ at a concentration which is certainly adequate to influence the excitability of any structure it has access to. The $\mathrm{K}^{+}$in the bathing solution could not, therefore, have access to them.

This is not only an explanation of the results of these particular experiments: it is a restatement of a well known fact. Substances which are known to give rise to pain when they are injected into the blood supply of a muscle, do not do so when they are injected directly into the body of the muscle (Moore, et al 1934). Once again, it would appear as though a barrier prevents an effective concentration of $\mathrm{K}^{+}$from accumulating in the immediate vicinity of the receptor ending.

Pain, as every athlete knows, can arise in muscles subjected to severe and prolonged activity, and it arises earlier in untrained than in trained persons. We offer, as a working hypothesis, the argument that the barriers reduce the rate at which $\mathrm{K}^{+}$accumulates in the effective environment of a receptor ending. Exceedingly high concentrations, as a result of prolonged and severe activity, could overcome the 'delaying' action and affect the ending. The barriers probably incorporate active processes driven by the metabolism of cells and these could increase in effectiveness in response to a challenge of high interstitial $\mathrm{K}^{+}$concentrations resulting from training procedures of adequate severity.

The work in Liverpool is supported by an M.R.C. grant The photography was performed by Miss Barbara Atherton

\section{REFERENCES}

1. ARESKOG, N. H., ARTURSON, G. \& GROTTE, G. (1965). Electrolyte composition and changes induced by cardiac glycosides. Biochemical Pharmacology 14, 783.

2. CHARLESWORTH, E. J. \& KIDD, G. L. (1971). A comparison of two forms of endurance training. British Journal of Physical Education. In press.

3. GLADDEN, M. H. \& KIDD, G.L. (1969). A technique for mapping intramuscular innervation. Journal of Applied Physiology 26, 507-510.

4. GURUMURTHY, I. \& KIDD, G. L. (1967). A technique for the intra-arterial injection of drugs into the caudal muscles of the rat. Laboratory Practice. 16, 34-37.

5. KIDD, G. L., KUCERA, J. \& VAILLANT, C. H. (1970). The rate of penetration of $\mathrm{K}^{+}$into the intertransverse caudal muscles of the rat. Journal of Physiology, 203, 87P.

6. KIDD, G. L., KUCERA, J. \& VAILLANT, C. H. (1971). The influence of the interstitial concentrations of $\mathrm{K}^{+}$on the activity of muscle receptors. Physiologia Bohemoslovaca. 20,95.

7. KJELLMER, J. (1961). The role of potassium ions in exercise hyperaemia. Experimental Medicine, 5, 56.

8. KJELLMER, J. (1965). The potassium ion as a vasodilator during muscular exercise. Acta Physiologica Scandinavica 63. 460.

9. MERRILLEES, N. C. R., (1960). The fine structure of muscle spindles in the lumbrical muscles of the rat. Journal of Biophysical and Biochemical Cytology, 71, 725.

10. MOORE, R. M., MOORE, R. E. \& SINGLETON, A. O. (1934). Experiments on the chemical stimulation of pain endings associated with small blood-vessels. American Journal of Physiology. 107: 594-602.

11. SHANTHA, T. R., GOLANZ, M. N. \& BOURNE, G. H. (1968). Histological and histochemical observations on the capsule of the muscle spindle in normal and denervated muscle. Acta anatomica 69: 632-646.

12. SHARP, R. S. (1971). On kinesthesis. British Journal of Physical Education 2, 5-8.

13. WILDENTHAL, K., MIERZWIAK, D. S., SKINNER, N. S. \& MITCHELL, H. J. (1968). Potassium-induced cardiovascular and ventilatory reflexes from the dog hindlimb. American Journal of Physiology, 215, 542. 